\title{
Radiation and Temperature Responses to a Small Clear-Cut in a Spruce Forest
}

\author{
K. Radler ${ }^{*, 1}$, A. Oltchev ${ }^{1,2}$, O. Panferov ${ }^{1}$, U. Klinck ${ }^{3}$ and G. Gravenhorst ${ }^{1}$ \\ ${ }^{1}$ Institute of Bioclimatology, Georg-August-University, Büsgenweg 2, D-37077 Göttingen, Germany \\ ${ }^{2}$ A.N. Severtsov Institute of Ecology and Evolution of RAS, Leninski Pr. 33, 119071, Moscow, Russia \\ ${ }^{3}$ Northwest German Forest Research Station, Department of Environmental Control, Grätzelstr. 2, D-37079 Göttingen, \\ Germany
}

\begin{abstract}
Effects of a small clear-cutting on solar radiation, soil and air temperature regimes were investigated by continuous field measurements in a spruce forest in Solling, Central Germany, during vegetation period of 2005. Five meteorological stations, installed in central part of a small clear-cut area $(2.5 \mathrm{ha})$ and close to edges of a surrounding forest, allowed to quantify the spatial variability of meteorological parameters within the clear-cut and to describe the impacts of the forest on clear-cut microclimate. The differences of microclimatic conditions between the clear-cut and the surrounding forest were derived using an additional station installed inside the forest about $150 \mathrm{~m}$ from the clear-cut. Results showed that clear-cutting leads to significant changes of spatial and temporal patterns of solar radiation and soil temperature. Solar radiation at the clear-cut was very heterogeneously distributed and about 5-11 times higher than inside the forest. It reached maximum at northeastern part and minimum at southwestern part of the clear-cut. The daily maximal soil temperature at $10 \mathrm{~cm}$ depth was measured at northern parts of the clear-cut and it was by up to $6^{\circ} \mathrm{C}$ higher than in the forest. Daily minimal soil temperature at the clear-cut was about $1-3^{\circ} \mathrm{C}$ higher than in the forest, too. The main factors influencing the soil temperature patterns were seasonally changed incoming solar radiation, ground vegetation and its phenology, as well as soil moisture. The mean daily maximal air temperature measured at the clear-cut was by up to $2.5^{\circ} \mathrm{C}$ higher and the mean daily minimal temperature by up to $0.5^{\circ} \mathrm{C}$ lower than in the surrounded forest.
\end{abstract}

Keywords: Spruce forest, small clear-cut, microclimate, field measurements, solar radiation, soil and air temperature.

\section{INTRODUCTION}

The conversion of Norway spruce (Picea abies) forests has become an important issue for forest management and research in Europe, and transformations of these forests into tree stands mixed with broadleaf species or into uneven-aged forests are aspired. The main objective of such conversions is to increase the ecological stability for those stands, and to make them more resistant against abiotic risks such as storm, snow and ice damage as well as against biotic ones like attacks of fungi and bark beetles. Possible effects of global climate change will most likely enhance such advantages. Moreover, as mixed forests are structurally more divers, they provide more ecological niches for associated fauna, flora and micro-organisms. This in turn improves the suitability of forested landscapes for nature conservation tasks. The conversion of pure spruce stands into mixed forests is also expected to improve the constitution of soils [1].

During the last decade a large part of Norway spruce monocultures in forests of the Lower Saxony of Germany has been converted into stands mixed with beech (Fagus sylvatica) and partially with Douglas fir (Pseudotsuga menziesii). Selective cutting has been used as the main silvicultural method, whereas a sufficient target diameter of

\footnotetext{
*Address correspondence to this author at the Institute of Bioclimatology, Georg-August-University, Büsgenweg 2, D-37077 Göttingen, Germany; Tel: 0049551 393683; E-mail: kradler1@gwdg.de
}

the trees was considered as main criteria for tree cutting. Recently, in order to accelerate the process of conversion the method of "small clear-cuts", i.e. 1-3 ha, is considered to be an acceptable alternative [2].

Most likely because leading silviculture paradigms had been favoring other types of forest management, there were surprisingly few experimental studies during the last decades which investigated the changes of micrometeorological conditions after small clear-cuts in a forest. More attention has been paid to effects of large (>10 ha) clear-cuts (e.g. [35]) and on effects of selective thinning (e.g. [6-8]) on forest microclimate. It was shown that such silvicultural methods result in significant changes of solar radiation, air and soil temperature, air humidity, ground surface precipitation, wind speed and direction that vary strongly between the clear-cut, edges and forest interior.

The relevant studies related to small clear-cuts usually focused on the ecological consequences of the microclimatic alterations after natural and artificial gap formation, i.e. small openings of less than two tree heights wide (e.g. [911]). Carlson and Groot [12] analyzed microclimatic conditions at small openings of various shapes and sizes up to 1.5 ha within a $19 \mathrm{~m}$ tall aspen forest, and found that the irradiance, soil temperature and extremes of air temperature increased with the size of the forest canopy opening. Similar results were obtained by Gray et al. [10] for photosynthetically active radiation (PAR) in gaps of 0.2 to 1.0 tree hights wide within an old-growth forest of Douglas 
fir and western hemlock. Additionally they showed, that PAR tends to decline within gaps from north via center to south positions, and this heterogeneity increased with gap size; a similar trend was found for the mean soil temperature pattern. Blennow [13] analyzed seasonal patterns of minimal air temperature at a clear-cut area and showed that the spatial pattern of temperature is also attributed to effects of topography which influence drainage, ponding and stagnation of cold air. All these studies complemented quantitatively more comprehensive the general results of classical microclimatological measurements in the forest provided and discussed by Geiger et al. [14].

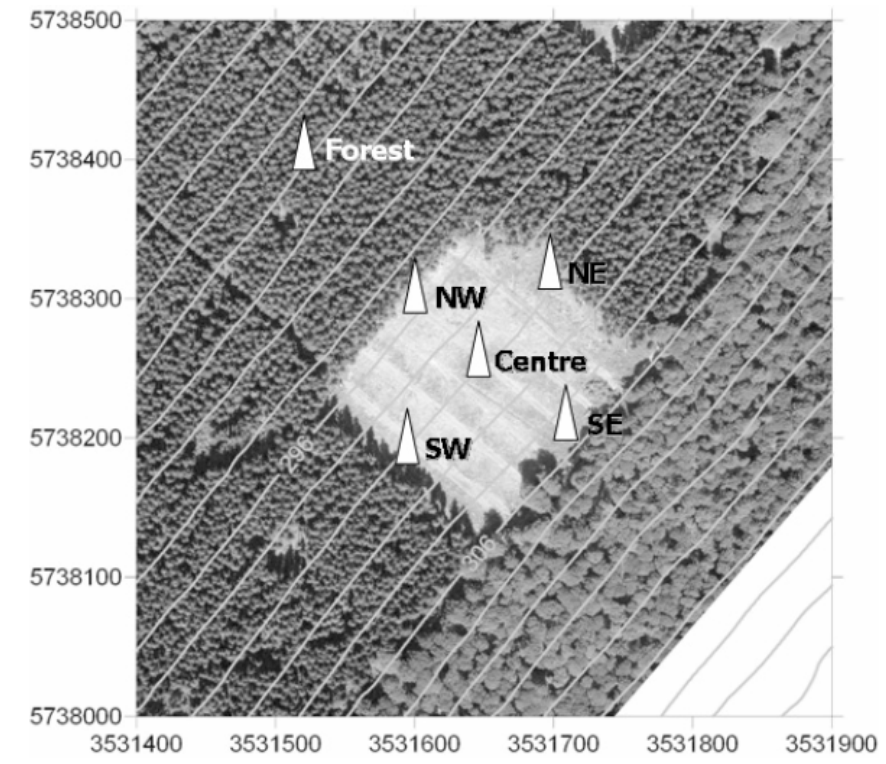

Fig. (1). Aerial photo of study area with locations of the measuring meteorological stations.

During the last decade several studies focused on estimation of clear-cutting and thinning effects on wind and turbulent exchange within atmospheric boundary and surface layers (e.g. [15-19]). In relation to forest microclimate such studies are very important because the turbulence regime is one of the main factors determining thermal and moisture status of ground surface and the atmospheric surface layer. The principal results of those field and modeling studies indicate that spatial and temporal wind patterns within the clear-cut are very heterogeneous, and they are strongly influenced by wind speed and direction, as well as by canopy structure and size of the clear-cut area.

For assessing the ecological consequences of small clearcuts as compared to the less influencing selective cutting, the Northwest German Forest Research Agency ("Nordwestdeutsche Forstliche Versuchsanstalt - NW-FVA") has initialized a long-term research program focused on comparisons of different harvesting techniques combined with several types of subsequent regeneration (Douglas fir or beech, artificial $v s$ natural regeneration, different schemes for planting of saplings). The main goal of these studies was to derive general guidelines for the practical forest management, taking into account different influencing factors such as inter- and intra-specific competition of the trees as well as soil and microclimatic conditions. As the latter factor can significantly influence many ecosystem processes, two questions arise: 1) How have microclimatic conditions changed after small clear-cutting (2-3 ha) and 2) How heterogeneous are these changes distributed within the clearcut area? To quantify those changes for the important environmental variables such as solar radiation, soil and air temperature was the main objective of this study. Particularily the latter target, the heterogenity of these parameters within a forest opening has not been in the focus of previous studies. Its quantitative knowledge, however, is obviously useful for a rational management of the regeneration of such areas. For solar radiation is the main source of energy for all life processes in forest ecosystems. It determines thermal and water regimes of ground surface and the atmospheric surface layer and influences transpiration and photosynthesis as the principal processes governing the forest growth. Air and soil temperatures are also key parameters determining the assimilation process of plants, and anomalous very high and low temperature may result in sapling damage or death (e.g. [20,21]).

\section{MATERIALS AND METHODOLOGY}

\section{Site Description}

The study site is located in central part of Germany about $60 \mathrm{~km}$ northwest of Goettingen in the Solling highland at $51^{\circ} 46^{\prime} \mathrm{N}$ and $09^{\circ} 27^{\prime} \mathrm{E}$, and about $300 \mathrm{~m}$ above see level. The clear-cut is 2.6 ha large and has a quadratic form $(160 \mathrm{~m} \times 160 \mathrm{~m})$ with diagonals going in south-north and eastwest directions and the forest edges have north-east, northwest, south-west and south-east orientation consequently. The area has a gentle north-western slope with inclination of $6^{\circ}$, so that two western sides are slightly lower than their eastern counterparts. The clear-cut is surrounded from three sides by a 85 year old and $35 \mathrm{~m}$ tall pure spruce stand and from south-east side - by a mixed stand of oak, ash and beach trees (Fig. 1). Trees have been felt in winter 2003 by a harvesting machine which also crushed the debris and gathered it at skidding lines. In spring 2004 the saplings of beech and Douglas fir have been planted at the clear-cut area into the bare soil in an experimental lattice of $1 \mathrm{~m}$ to $3 \mathrm{~m}$. Vegetation of different herbaceous species has nearly covered the whole area of the clear cut. Along the south-west border a $20 \mathrm{~m}$ wide band is partially covered with natural regeneration of spruce of heights between $20 \mathrm{~cm}$ and 250 $\mathrm{cm}$. In the southern one-third of the area there are smaller and greater patches covered with great fern (Pteridium aquilinum). The podsolic mineral soil is covered by moder humus with a thickness of about $5 \mathrm{~cm}$. The soil derives from new-red-sandstone, which is covered by a loess layer of up to $1 \mathrm{~m}$. Its main fraction is silt $(84 \%)$ followed by equal portions of clay and sand (8\%).

\section{Field Measurements}

The temporal and spatial patterns of microclimatic conditions at our study area were derived from continuous measurements provided by 6 meteorological stations. Five of those were installed at the clear-cut area (see Fig. 1), one in the centre (Centre) and one - at $12 \mathrm{~m}$ distance $(1 / 3$ of tree height) to each of four edges (tree lines): north-western $(\mathrm{NW})$, north-eastern (NE), south-western (SW), and southeastern (SE). The sixth station was placed about $150 \mathrm{~m}$ to the north-west from the clear-cut within the remained forest and used as a reference (Forest). Each station was equipped with sensors for wind direction and speed, global solar radiation, 
air temperature, relative humidity and precipitation mounted at $2 \mathrm{~m}$ above a ground surface, as well as with sensors for soil temperature installed in mineral soil layer at depths of 10 $\mathrm{cm}$ and $20 \mathrm{~cm}$.

Global solar radiation was measured by means of pyranometers CM3 (Kipp \& Zonen, Nederlands), which allow to measure the incoming shortwave radiation within the spectral waveband from 300 to $2500 \mathrm{~nm}$. Air temperature and relative humidity were measured using a platinum resistance thermometer (Pt100) and a capacitive humidity probe in an electrically aspirated shelter (TypeNo. 3030.1000, Theodor Friederichs, Germany) respectively. Soil temperature was measured using a Pt100 sensor installed inside a stainless steel tube of $10 \mathrm{~cm}$ length (TypeNo. 2018.0000, Theodor Friederichs, Germany). For data recording and storage the data logger COMBILOG (Theodor Friederichs, Germany) was used.

The measurements were sampled with $0.1 \mathrm{~Hz}$ frequency and stored as 5-minute averages during the vegetation period of 2005 (from April to October 2005).

Estimates of the sky view factor for our measuring sites were based on fisheye-fotos taken by the camera Nikon Coolpix 4500 equipped by lense FC-E8 $0.21 \mathrm{x}$ with an aperture angle of $180^{\circ}$. Hemispherical photos were analyzed by the WinScanopy software.

\section{Data Analysis}

The temporal and spatial variability of incoming shortwave radiation $(\mathrm{R})$ within the clear-cut area was quantified using 5 minute averaged $\mathrm{R}\left(\mathrm{W} \mathrm{m}^{-2} \mathrm{~s}^{-1}\right)$, the daily radiation sums $\mathrm{R}(\mathrm{d})\left(\mathrm{MJ} \mathrm{m} \mathrm{m}^{-2} \mathrm{day}^{-1}\right)$, as well as the weekly $\mathrm{R}(\mathrm{w})$ and seasonally $\mathrm{R}(\mathrm{s})$ averaged $\mathrm{R}\left(\mathrm{MJ} \mathrm{m}^{-2} \mathrm{day}^{-1}\right)$ data. To compare radiation regime between the clear-cut and the forest $R(d)$ and $R(s)$ data were used. To quantify shading effects of the surrounding forest on $R$ the ratios $Q_{i}$ of solar radiation at different parts of the clear-cut $R_{i}(i=N W, N E$, $\mathrm{SW}, \mathrm{SE}$ ) and at clear-cut center (Centre) were calculated, i.e. $\mathrm{Q}_{\mathrm{i}}=\mathrm{R}_{\mathrm{i}} / \mathrm{R}_{\text {Centre }}$

To describe the spatial and temporal patterns of soil and air temperature we calculated daily mean $\mathrm{T}_{\text {mean }}$, daily maximal $T_{\max }$ and minimal $T_{\min }$ values as well as daily amplitudes A of soil and air temperature. The seasonal averages of these parameters were used for quantifying the differences of the overall seasonal heat gain between measuring sites [20]. To reveal a possible seasonal change of the difference between forest and central part of the clear-cut we considered the differences of the daily maximal $\Delta \mathrm{T}_{\max }=$ $\mathrm{T}_{\text {Max_Centre }}-\mathrm{T}_{\text {Max_Forest }}$ and minimal $\Delta \mathrm{T}_{\min }=\mathrm{T}_{\text {min_Centre }}$ $\mathrm{T}_{\text {Min_Forest }}$ temperature. To quantify the spatial differences of the seasonal dynamics of $T_{\max }$ and $T_{\min }$ within the clear-cut, the temperature differences between clear-cut borders $T_{i}(i=$ $\mathrm{NW}, \mathrm{NE}, \mathrm{SW}, \mathrm{SE})$ and clear-cut center $\left(\Delta \mathrm{T}_{\mathrm{i}}=\mathrm{T}_{\mathrm{i}}-\mathrm{T}_{\text {Centre }}\right)$ were calculated. Thereby two week averages of $T_{\min }$ and $T_{\max }$ were used, in order to reduce the influence of short-term temperature fluctuations.

Visual control of data quality, gap filing, data aggregating and analysis were performed by means of SAS software [22].

\section{RESULTS AND DISCUSSION}

\section{Solar Radiation}

Results of the field measurements show that clear-cuting results in drastical increases of solar radiation (Table 1): The highest overall solar irradiance $R(s)$ is observed at the centre of the clear cut, as compaired to the forest site it is elevenfold higher. Shading from surrounding forest stands provides very heterogeneous spatial and temporal distributions of solar radiation within a clear-cut area. The sky view factor for the border measuring sites ranged from $64 \%$ to $77 \%$ of the centre sky view (Table 1). At the two northern sites of the clear cut about $80 \%$ to $90 \%$ of the irradiance at the central station were measured. Two southern sites of the clear cut receive significantly less solar radiation than the central and northern sites.

The seasonal trends of incoming radiation $\mathrm{R}(\mathrm{d})$ are characterized by clear maximum in summer months reaching $30 \mathrm{MJ} \mathrm{m}^{-2}$ day $^{-1}$ at clear-cut centre and $2.6 \mathrm{MJ} \mathrm{m}^{-2}$ day $^{-1}$ at the forest site (Fig. 2a). The variing conditions of cloudiness cause at the clear-cut the immense day-to-day variability of radiation, which amounted to up to $25 \mathrm{MJ} \mathrm{m}^{-2}$ day $^{-1}$ vs one tenth of that only in the forest, because of the very low penetration of direct radiation under the forest canopy (e.g. [23]).

Apart from short-term variability due to changes of cloudiness, the ratio $Q_{i}=R_{i} / R_{\text {centre }}$ (Fig. 2b) shows clear seasonal trends for all clear-cut stations. The highest $\mathrm{Q}$ values were always observed at the NE site. They vary around $87 \%$ from spring until the middle of August, and in autumn they reach a maximum of close to $100 \%$. The pattern of $\mathrm{Q}$ for the NW is quite similar to that of the NE site, however, caused by the smaller sky view factor (Table 1), about 5\% smaller. The $\mathrm{Q}$ variability at the SW site exhibits the biggest short-term variations with higher values on prevailing cloudy weather conditions and lower ones in periods with dominating sunny weather. It varies around a mean of about $55 \%$ until the middle of August, while during the autumn months it shows a stable decreasing trend down to $20 \%$. The seasonal course of Q at the SE site is very close to courses of $\mathrm{Q}$ at the northern sites during the period from April to August, while later on it decreases drastically down to $27 \%$ in autumn.

Table 1. Mean daily $\left(R_{i}\right)$ and Normalized $\left(Q_{i}=R_{i} / R_{\text {Centre }}\right)$ Solar Radiation, Measured During the Period from 1 April to 31 October 2005 at Clear-Cut and Forest Sites, and Sky View Factors Derived from Hemispherical Photos $\left(\mathrm{SV}_{\mathrm{i}}\right)$ and Normalized with Sky View at Centre Station $\left(S_{V Q} Q_{i}=S V_{i} / S V_{\text {Centre }}\right)$

\begin{tabular}{|c|c|c|c|c|}
\hline Station & $\mathbf{R}_{\mathbf{i}}\left(\mathbf{M J ~ m}^{-2} \boldsymbol{D a y}^{-\mathbf{I}}\right)$ & $\mathbf{Q}_{\mathbf{i}}$ & $\mathbf{S V}_{\mathbf{i}}(\mathbf{\%})$ & $\mathbf{S V Q}_{\mathbf{i}}(\mathbf{\%})$ \\
\hline \hline Centre & $13.8 \pm 7.0$ & 1.00 & 80 & 100 \\
\hline North-West & $11.4 \pm 5.8$ & 0.83 & 55 & 69 \\
\hline North-East & $12.1 \pm 6.2$ & 0.88 & 63 & 79 \\
\hline South-West & $6.8 \pm 3.9$ & 0.49 & 53 & 66 \\
\hline South-East & $10.0 \pm 5.9$ & 0.72 & 63 & 79 \\
\hline Forest & $1.2 \pm 0.5$ & 0.09 & 13 & 16 \\
\hline
\end{tabular}


Thus, the seasonal pattern of radiation within the clearcut area is characterised by fairly constant and least deviating ratios during summer months and late spring and by an increasing heterogeneity in autumn and early spring. The southern clear-cut parts receive less radiation compared to the open central part, while northern parts get almost the same amount as the center. The main reason for these variations within the clear-cut is the site-specific shading of direct solar radiation by surrounding trees, which with decreasing solar elevation cut off a steadily increasing portion of the daily radiation at southern sites. The chosen experimental clear-cut of Otterbach is somewhat particular because its south-eastern edge is bordered by a deciduous mixed stand. That complicates the spatial and (especially) temporal pattern of solar radiation within the clear-cut since the radiative regime is strongly controlled by structure of the surrounding forest and the latter in turn depends on phenological phase especially for deciduous tree species.

To exhibit the reasons for the spatial and temporal heterogeneity of solar radiation regime within the clear-cut area the daily courses of two sunny days were additionally investigated (Fig. 2c). The two selected cloudless days, April 22 and August 18, are characterised by the same day length and sun inclinations, and they were chosen to quantify the effect of varied phenological phases of the surrounding broadleaf trees on solar radiation regime at different parts of

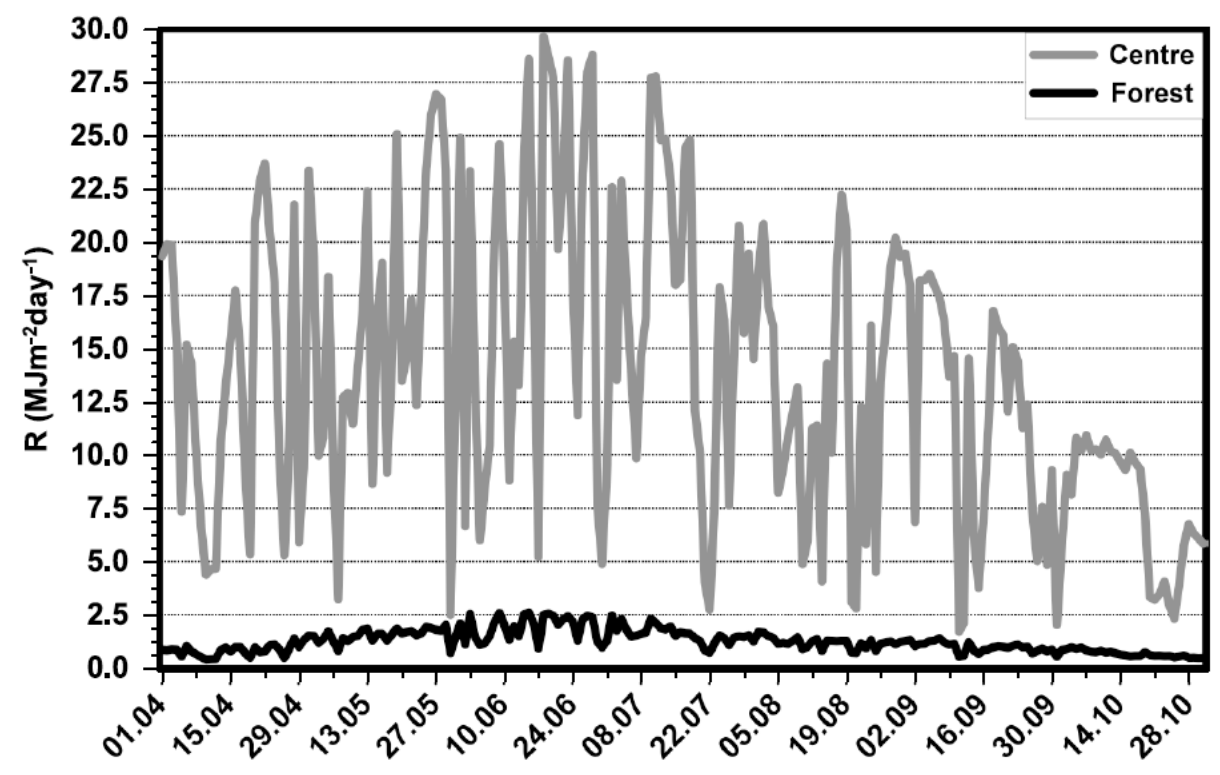

Time

Fig. (2a). Seasonal courses of daily solar radiation sums (R) measured by stations in the centre of clear-cut area and at reference station within the forest during the study period from April to October 2005.

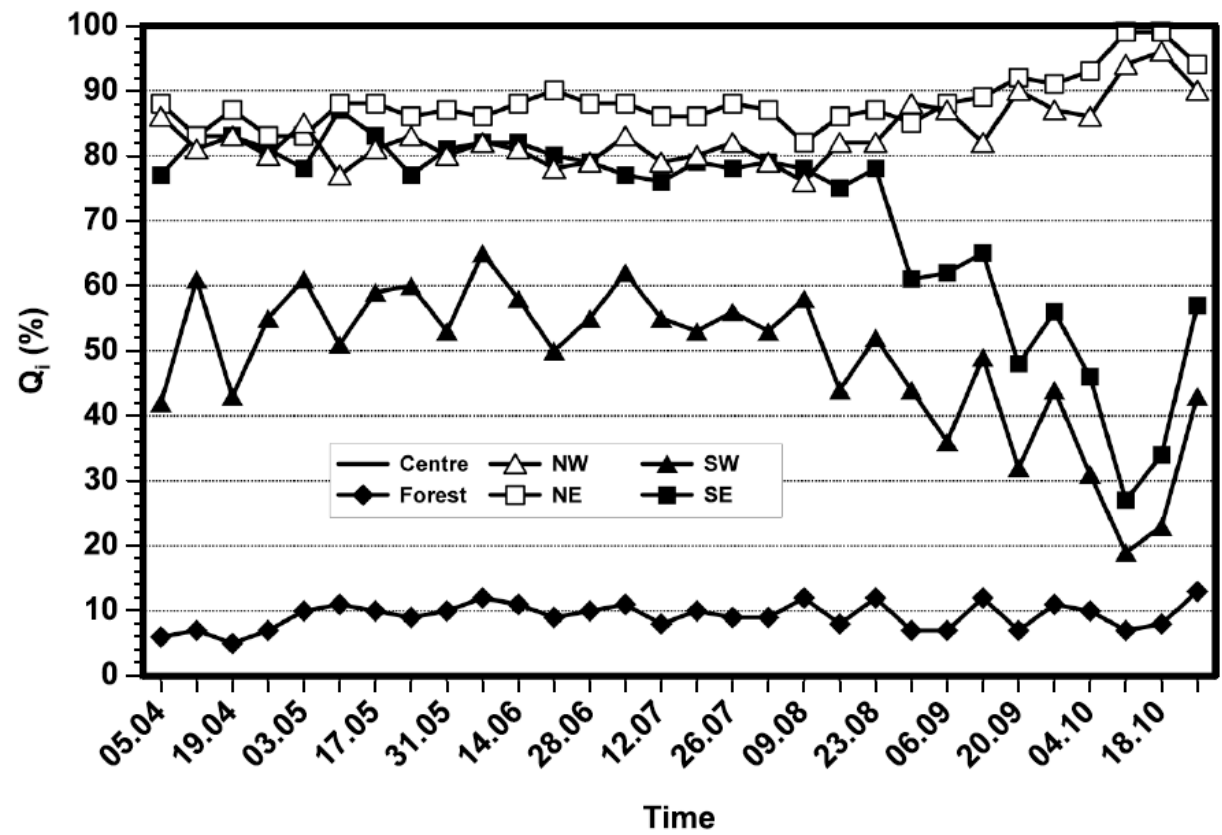

Fig. (2b). Seasonal course of the ratio $Q_{i}=R_{i} / R_{\text {centre, }}$ where $R_{i}$ ist the daily radiation sum (weekly means) measured at the clear-cut borders (NW, NE, SW, SE), its centre (Centre) and in the forest (Forest). 

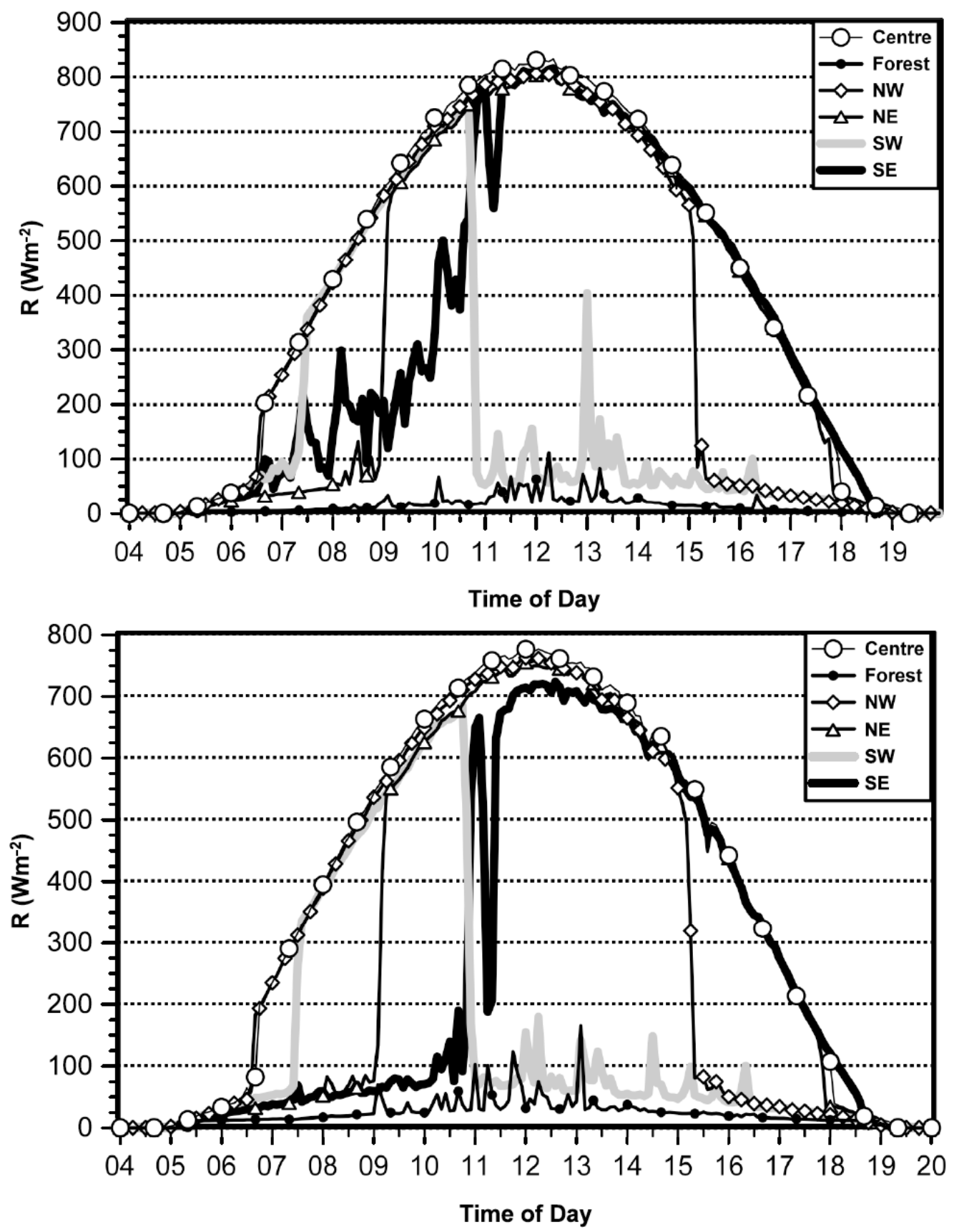

Fig. (2c). Diurnal course of incoming shortwave solar radiation (5 min. averages) at the five clear-cut sites and in the forest for two cloudless days ( $22^{\text {th }}$ April above and $18^{\text {th }}$ August below). Selected days are characterised by the same day length.

the clear-cut area. Comparisons of solar radiation regime at the SE station located closely to the broadleaf forest show that on April 22 the radiation was from sunrise until 11 a.m. much higher and much more variable than on August 18. This difference results from the shading caused by the deciduous forest neighboring the clear-cut from south-east: While in April the buds of trees had been just beginning to burst and the shading was caused by tree stems only, in August all leaves had been fully developed, the canopy is closed and up to $90 \%$ of radiation is absorbed by leaves [23]. Therefore, the direct solar radiation, which comes from south-east directions during the morning hours and penetrates through the deciduous stand at the SE border of the clear-cut area, is at the SE measuring site much higher in
April than in August. It is also obvious that the shading by stems (in April) causes much higher variability of radiation than the shading by canopy with completely developed folliage (in August). The phenological effect of a steady increment of leaf area in the neighboring deciduous forest stand is visible in Fig. (2b), too, for the trend line of the SE station reveals from April to August a slight but distinct diminishing.

With the exception of the reference forest plot, all curves of Fig. (2c) are by about 10-50 $\mathrm{W} \mathrm{m}^{-2}$ higher on April 22 than on August 18. To this difference certainly contributes the greater sky view area due to the missing foliage on broadleaf trees, as has been shown by a modelling study on 
this area. Moreover, to the difference observed between the two days could contribute a lower atmospheric transmittance in August, as such effect has been observed at a similar clear-cut area located several kilometres away from the Otterbach study site. Possible reasons for this could be the nearly three times higher content of water vapour, and possibly more airborn particles in the atmosphere. Since higher turbidity of the atmosphere resulted in changes of the ratio between direct and diffuse solar radiation in the total radiation flux, it could have contributed to the somewhat higher solar radiation sum in the forest, because diffuse radiation penetrates better into the forest than direct solar radiation.

Apart from this phenological effect Fig. (2c) reveals, that the duration of direct solar radiation differed substantially among our measuring sites on the clear-cut area: for the selected days sunshine duration at the $\mathrm{SW}$ site was about 3.5 hours only, as compared to about 7 hours at the SE site. This is probably the most influential difference between the two southern sites. The sunshine duration at the two northern sites was 9 hours, and their daily courses are symmetrical to each other around their maximum at noon. The sunshine duration at central clear-cut site was 11.5 hours for both days.

Table 2 shows the daily sums of solar radiation for the selected sunny days as well as two overcast days with nearly the same sun elevation. For the two sunny days the longest duration of direct solar radiation together with the largest sky view area resulted in the biggest radiation gain at centre of the clear-cut. Compared to the forest the ground (vegetation) surface of this site received 30 times more radiation on April 22 . The two northern sites received about $15 \%$ less, and the SW site nearly $65 \%$ less radiation than the central station, on both sampled days. If we assume about $1 \mathrm{MJ} \mathrm{m}^{-2} \mathrm{day}^{-1}$ less atmospheric transmittance on August 18, then the fully developed leaves caused a reduction of about $3 \mathrm{MJ} \mathrm{m}^{-2} \mathrm{day}^{-1}$ or $17 \%$ at the SE border of the clear-cut.

The solar radiation sums at the two overcast days evinced narrower relations between both the centre and the forest sites, and the southern and the centre sites on the clear-cut. The radiation reduction is least in the forest (ca. $0.5 \mathrm{MJ} \mathrm{m}^{-2}$ day $^{-1} \sim 50 \%$ ) and largest at the centre of the clear-cut (ca. 19 MJ $\mathrm{m}^{-2}$ day $^{-1} \sim 85 \%$ ).

Table 2. Comparison of daily Sums of Solar Radiation $R_{i}\left(M_{J} ~ m^{-2}\right.$ day $\left.^{-1}\right)$ Measured for 4 Selected Days in Spring and Summer (i.e.

$\sim 2$ Months Before and After Summer Solstice) Characterized by Cloudless and Overcast Sky Conditions. $Q_{i}=R_{i} / R_{C e n t r e}$ (See Fig. 2c)

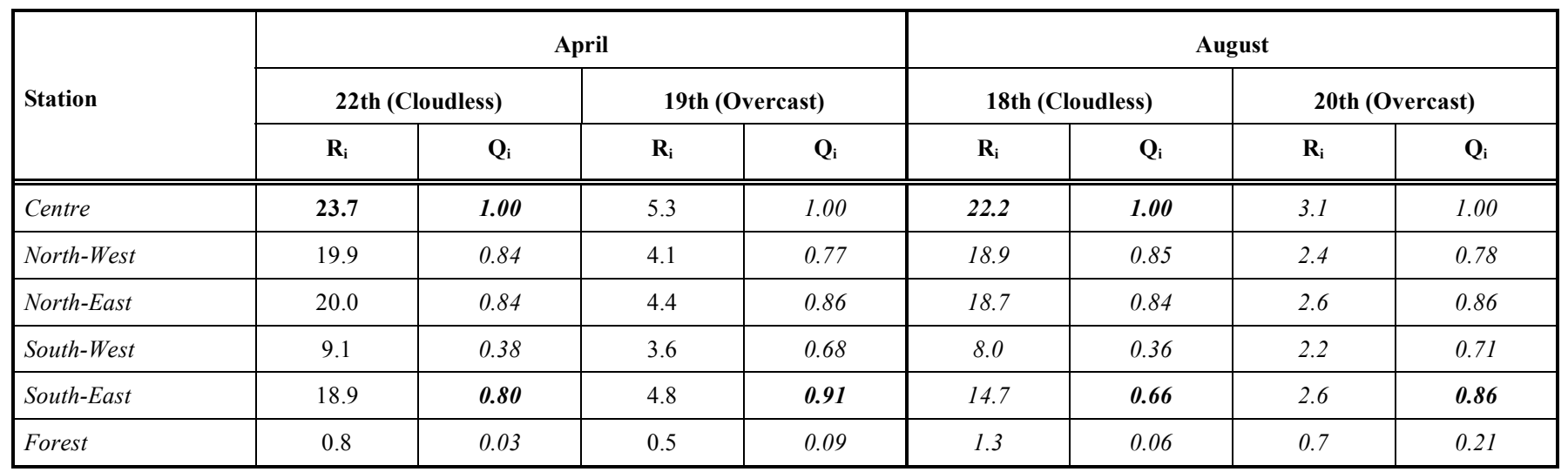

\section{Soil Temperature}

The properties of the ground surface layer are very heterogeneous on the clear cut, mainly due to heterogeneity of the vegetation/ground cover as well as the structure, composition and moisture of the upper soil layers. Nevertheless a spatial pattern of the soil temperature at $10 \mathrm{~cm}$ depth was found consistent with the solar irradiance distribution. The centre of the clear cut and the two northern sites show higher values of the mean, the daily maximal and minimal soil temperatures compared to the two southern sites. The soil temperature of the forest site was still lower than of the two southern sites (Table 3). The average daily amplitude was only $0.6^{\circ} \mathrm{C}$ in the forest, but it ranged from $1.0^{\circ} \mathrm{C}$ to $1.9^{\circ} \mathrm{C}$ among the five clear-cut sites. Among the five clear-cut stations the maximal difference for the mean soil temperature was $1.2^{\circ} \mathrm{C}$, and for the averaged daily maximal and the minimal values $1.5^{\circ} \mathrm{C}$ and $1.3^{\circ} \mathrm{C}$, respectively.

The seasonal course of the daily maximal and minimal temperatures at central part of the clear-cut and at the reference forest site shown in Fig. (3a) indicates that from early spring (the beginning of measuring campaign) to the hottest summer period in July/August the soil temperature increased by $13^{\circ} \mathrm{C}$ at clear-cut sites and by $9^{\circ} \mathrm{C}$ at the had been observed in late July, was about $20^{\circ} \mathrm{C}$ at the clearcut and nearly $16^{\circ} \mathrm{C}$ in the forest. From May to September the daily minimum of soil temperature at the clear-cut was always higher than the daily maximum in the forest. The differences between clear-cut and forest ranged for the maximal temperature $\left(\Delta \mathrm{T}_{\max }=\mathrm{T}_{\text {Max_Centre }}-\mathrm{T}_{\text {Max_Forest }}\right)$ from $0.0^{\circ} \mathrm{C}$ to $4.5^{\circ} \mathrm{C}$ and for the minimal temperature $\left(\Delta \mathrm{T}_{\min }=\right.$ $\mathrm{T}_{\text {Min_Center }}-\mathrm{T}_{\text {Min_Forest }}$ ) from $-1.0^{\circ} \mathrm{C}$ to $3.2^{\circ} \mathrm{C}$. Peak values occurred for $\Delta \mathrm{T}_{\max }$ in May and July, and for $\Delta \mathrm{T}_{\min }$ from late May to the beginning of August. In seasonal course $\Delta \mathrm{T}_{\max }$ was always up to $2^{\circ} \mathrm{C}$ larger than $\Delta \mathrm{T}_{\min }$.

The seasonal course of the daily amplitudes $A$ (Fig. 3b) exhibits heterogeneous trends in spring, and for all stations a decreasing trend from the middle of May to the end of the vegetation period. For clear-cut stations these patterns could be influenced by ground vegetation cumulating in the clearcut area from May to October. It intercepts solar radiation during daytime and reduces the long-wave emission from the reference forest plot. The highest soil temperature, which 
soil surface during the night [24]. The smallest $A$ and the lowest variation of $A$ were observed at the reference forest station. Among the clear-cut sites the NW site had the smallest $A$ throughout the study period. It ranged from $0.4^{\circ} \mathrm{C}$ to $1.6^{\circ} \mathrm{C}$, and it was very similar to the $A$ course at the Central station, however, always about $1^{\circ} \mathrm{C}$ lower. The $A$ courses at $\mathrm{NE}$ and $\mathrm{SW}$ sites were quite similar during the measuring period, and differed by less than $0.5^{\circ} \mathrm{C}$. The highest seasonal variability of $A$ was observed at SE site, where it reached its maximum of $3^{\circ} \mathrm{C}$ in late May, while in summer and autumn it decreased to values of less than $1^{\circ} \mathrm{C}$. The reason for such trend is probably the variability of solar radiation reaching the soil surface, which is influenced, on the one hand, by weather conditions and, on the other hand, by phenological changes in the neighboring deciduous forest (see previous section) and by the dense vegetation cover of fern species growing around the measuring plot.

Table 3. Mean Daily $T_{\text {mean }}$, Daily Maximal $T_{\max }$, Daily Minimal $T_{\min }(0: 00-8: 00)$ Soil Temperature $\left({ }^{\circ} \mathrm{C}\right)$ at $2 \mathrm{~m}$ a.g.l., and their Daily Amplitude $A=T_{\text {max }}-T_{\text {min }}$ with Standard Deviations for Five Clear-Cut and the Forest Reference Sites Averaged for Measuring Period from April to October 2005

\begin{tabular}{|c|c|c|c|c|}
\hline Station/Site & $\mathbf{T}_{\text {mean }}$ & $\mathbf{T}_{\max }$ & $\mathbf{T}_{\min }$ & $\mathbf{A}$ \\
\hline \hline Clear-cut Centre & $13.6 \pm 3.0$ & $14.6 \pm 3.0$ & $12.7 \pm 3.1$ & $1.9 \pm 0.8$ \\
\hline North-West & $13.4 \pm 2.8$ & $13.9 \pm 2.7$ & $12.9 \pm 2.8$ & $1.0 \pm 0.5$ \\
\hline North-East & $13.6 \pm 3.3$ & $14.5 \pm 3.4$ & $12.8 \pm 3.2$ & $1.7 \pm 0.8$ \\
\hline South-West & $12.4 \pm 3.3$ & $13.1 \pm 3.4$ & $11.6 \pm 3.3$ & $1.5 \pm 0.7$ \\
\hline South-East & $12.6 \pm 2.8$ & $13.4 \pm 2.8$ & $11.8 \pm 3.0$ & $1.6 \pm 1.1$ \\
\hline Forest & $11.1 \pm 2.6$ & $11.4 \pm 2.6$ & $10.8 \pm 2.6$ & $0.6 \pm 0.3$ \\
\hline
\end{tabular}

The seasonal course of the spatial patterns of maximal and minimal soil temperature within the clear-cut shows (Fig. 3c), that the differences $\Delta \mathrm{T}_{\mathrm{i}}=\mathrm{T}_{\mathrm{i}}-\mathrm{T}_{\text {Centre }}$ between clearcut center and clear-cut borders (NW, NE, SW, SE) changed significantly during the measuring period. They ranged between $+1.5^{\circ} \mathrm{C}$ and $-3.0^{\circ} \mathrm{C}$ for the daily maximal, and between $+1.0^{\circ} \mathrm{C}$ and $-2.0^{\circ} \mathrm{C}$ for the daily minimal values. Since the value of maximal soil temperature is mainly determined by incoming solar radiation absorbed by ground surface, their seasonal course should have a trend similar to the radiation pattern. However, although the incoming solar radiation in clear-cut center is larger than at clear-cut borders, the maximal soil temperature at the NE site is up to $1.2^{\circ} \mathrm{C}$ higher than at clear-cut centre during June and July.

Such difference could be explained by lower turbulent exchange in the vicinity of the surrounding forest as has been shown by several modelling studies (e.g. [16, 18]). It may also be explained by a stronger reduction of soil moisture at this part of the clear-cut resulting in lower thermal conductivity of the upper soil layers, and here indicated by a larger daily temperature amplitude (see Fig. 3b) of the upper soil layer $(0-10 \mathrm{~cm})$. At the SW site the seasonal course of the deviation (from centre site) seems to follow the trend of the relative radiation gain at this station (see Fig. 2b), i.e. least deviating around summer solstice, and more deviating in spring and autumn for both maximal and minimal temperatures. At the SE site a similar effect seems to be involved in the period of late spring, but in the following month of July the maximal soil temperature exhibits a steep relative decrease to a level that was $2.0-2.5^{\circ} \mathrm{C}$ lower than the temperature at the Centre site. This is most likely influenced by a reduced radiation gain due to foliage development in the neighboring deciduous forest. In addition, the soil surface around our measuring sensor at SE site was covered by

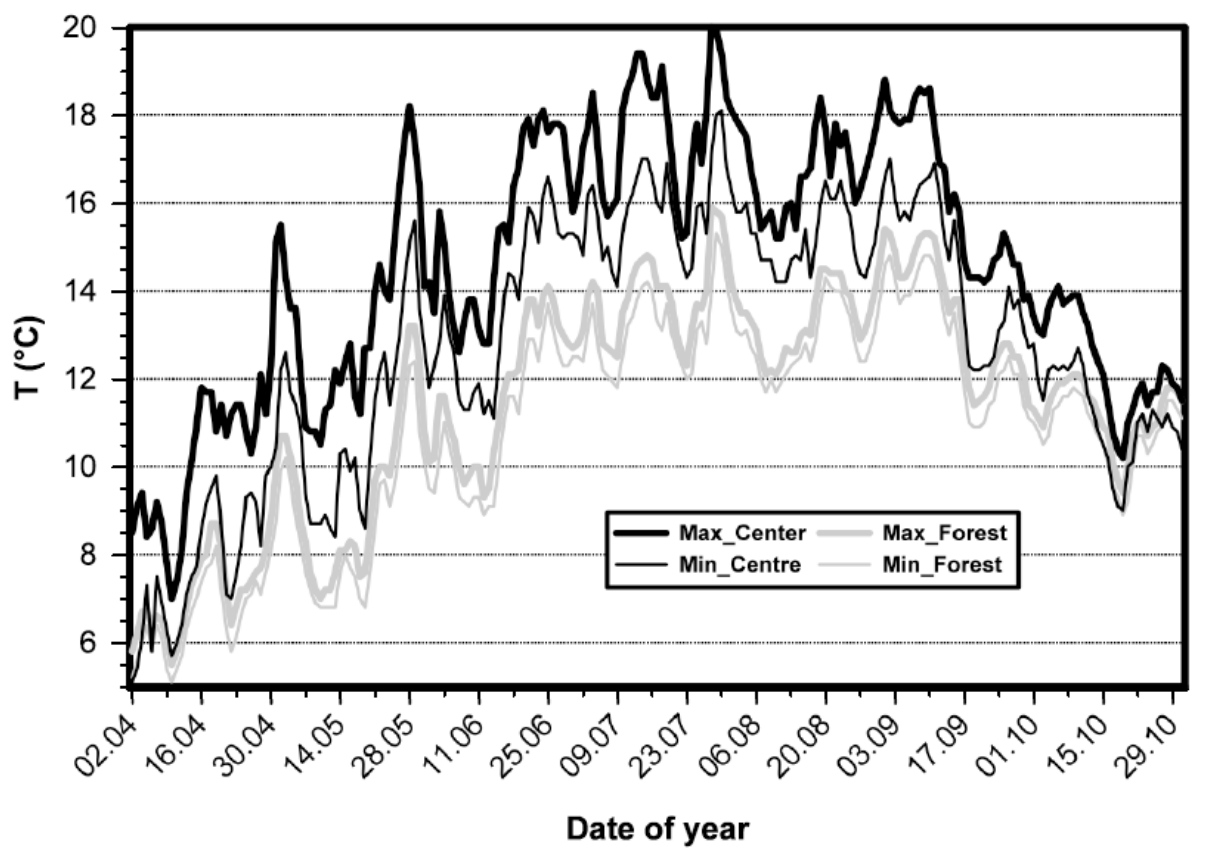

Fig. (3a). Seasonal course of daily maximum and minimum of soil temperature (T) measured by stations in the centre of clear-cut area and within the forest for study period from April to October 2005. 


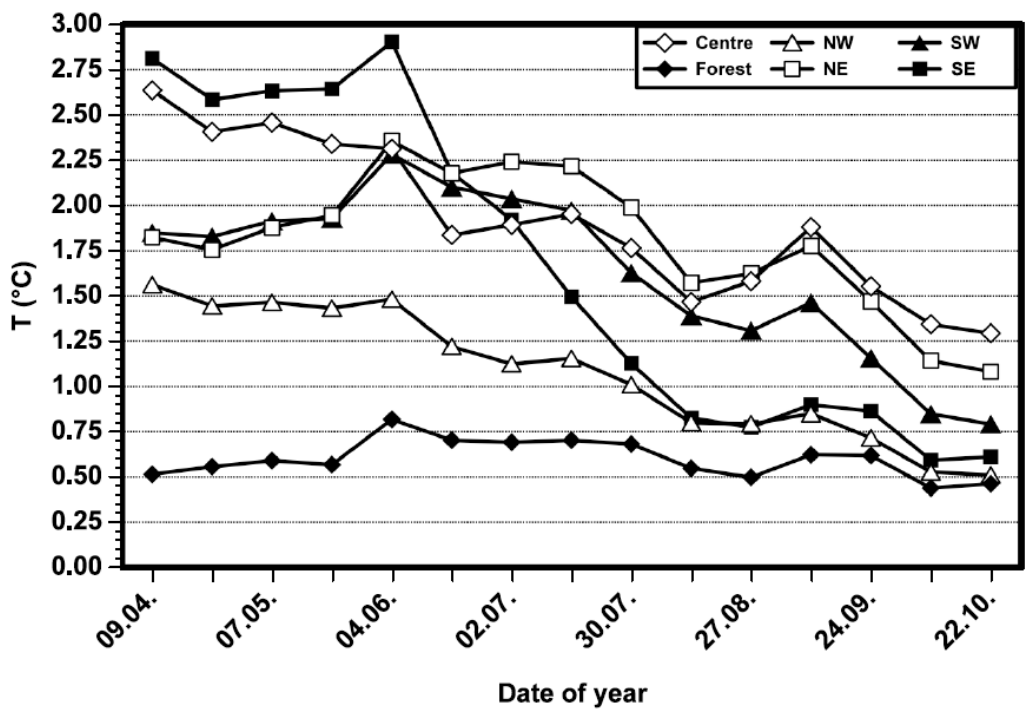

Fig. (3b). Seasonal course of mean daily amplitude (two weeks averaging) of soil temperature at the five measuring stations on the clear-cut area and at the reference forest station during the study period from April to October 2005.

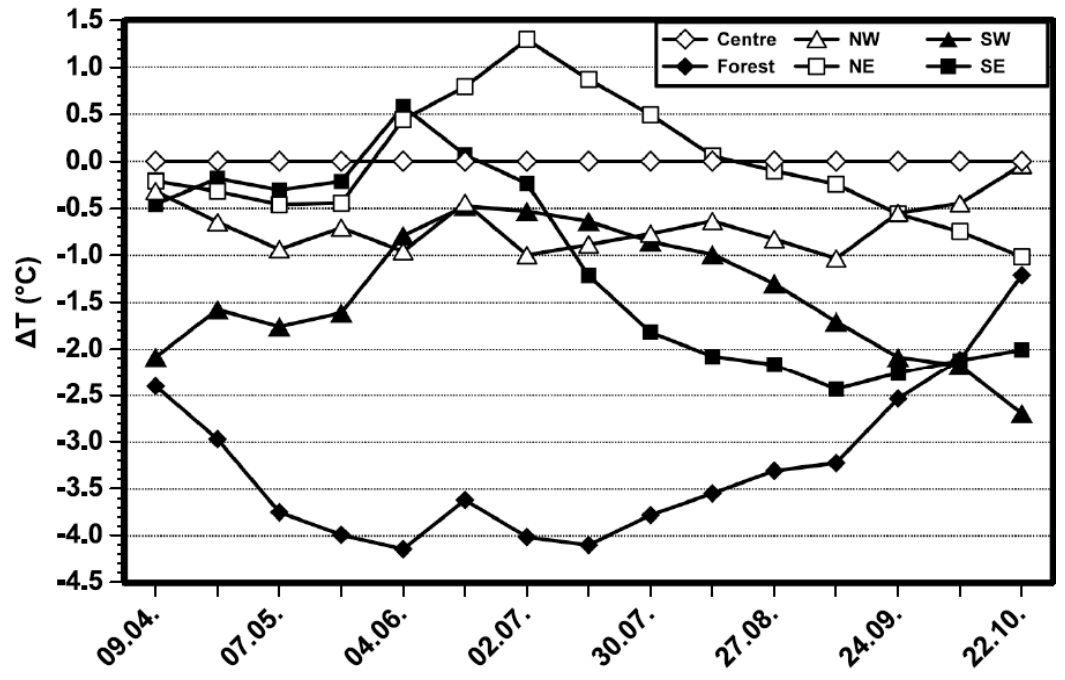

Date of year

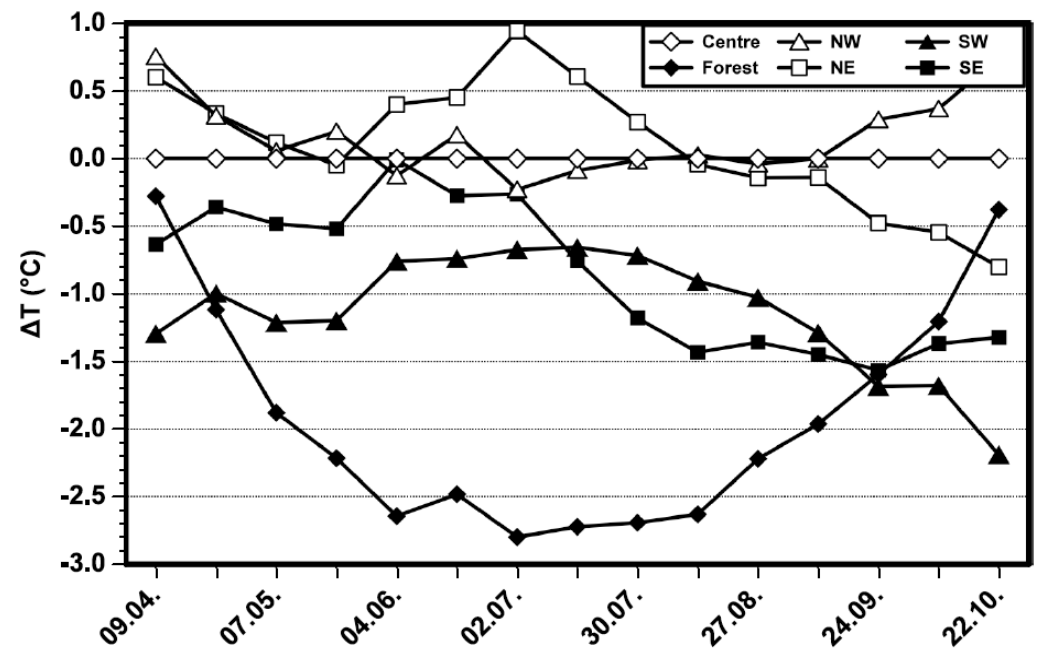

Date of year

Fig. (3c). Seasonal course of mean daily maxima (above) and minima (below) of soil temperature at all measuring sites during the study period from April to October 2005. Values are plotted as deviations from the respective value at the central station $\Delta \mathrm{T}_{\mathrm{i}}=\mathrm{T}_{\mathrm{i}}-\mathrm{T}_{\mathrm{Centre}}$. 
dense ground vegetation of a fern species (Pteridium aquilinum), which started foliating in late June and absorpted increasingly more of the incoming solar radiation in August and September.

The daily minimal temperature mainly depended on weather conditions of the night, but was also strongly influenced by temperature conditions of the previous day. Thus, their seasonal dynamics is very similar to the course pattern of the maximal temperature for all clear-cut sites (Fig. 3c). At the southern sites minimal soil temperature is always, up to $2.0^{\circ} \mathrm{C}$, lower than at the clear-cut centre. At the NW site minimal soil temperature is quite similar to values at clear-cut centre during the summer period, while it is always larger than in clear-cut centre during spring and autumn. At NE site $\Delta \mathrm{T}_{\min }$ has a seasonal trend, which is very similar to the trend of $\Delta \mathrm{T}_{\max }$.

\section{Air Temperature}

The results of provided measurements show a small spatial variability of the air temperature within the clear-cut as well as a little difference between the clear-cut and the reference forest site as compaired to soil temperature patterns. The seasonally averaged temperatures (Table 4) differed between the clear-cut centre and the reference forest plot by $0.3^{\circ} \mathrm{C}$ only. For the daily maximal temperature this difference is more significant $\left(+1.7^{\circ} \mathrm{C}\right)$ while the difference of daily minimal values is negative and relatively small $\left(-0.3^{\circ} \mathrm{C}\right)$ too. The mean daily amplitude of air temperature is at the clear-cut centre $2{ }^{\circ} \mathrm{C}$ larger than at the forest site. The corresponding temperature range among the five clear-cut sites was of the same order of magnitude, i.e. $0.6^{\circ} \mathrm{C}$ for the daily mean, $1.2^{\circ} \mathrm{C}$ for daily maximal $\mathrm{T}_{\max }$, and $0.4^{\circ} \mathrm{C}$ for daily minimal temperature $\mathrm{T}_{\min }$. Variability of daily amplitude A within the clear-cut sites does not exceed $1^{\circ} \mathrm{C}$. The pattern of average $T_{\max }$ mirrors generally the radiation and soil temperature pattern, i.e. at the central and the northern sites it is higher than at both the southern and the forest sites.

Table 4. Mean Daily $T_{\text {mean }}$, Daily Maximal $T_{\max }$, Daily Minimal $T_{\min }(0: 00-8: 00)$ Air Temperature $\left({ }^{\circ} \mathrm{C}\right)$ at $10 \mathrm{~cm}$ Depth, and their Daily Amplitude $A=T_{\text {max }}$ $T_{\min }$ with Standard Deviations for Five Clear-Cut and the Forest Reference Sites Averaged for Measuring Period from April to October 2005

\begin{tabular}{|l|c|c|c|c|}
\hline \multicolumn{1}{|c|}{ Station/Site } & $\mathbf{T}_{\text {mean }}$ & $\mathbf{T}_{\max }$ & $\mathbf{T}_{\min }$ & $\mathbf{A}$ \\
\hline \hline Clear-cut Centre & $13.7 \pm 4.5$ & $19.2 \pm 5.6$ & $9.3 \pm 4.1$ & $9.9 \pm 3.5$ \\
\hline North-West & $13.7 \pm 4.6$ & $18.9 \pm 5.6$ & $9.4 \pm 4.2$ & $9.5 \pm 3.5$ \\
\hline North-East & $13.8 \pm 4.5$ & $19.2 \pm 5.6$ & $9.5 \pm 4.1$ & $9.7 \pm 3.6$ \\
\hline South-West & $13.4 \pm 4.5$ & $18.0 \pm 5.2$ & $9.3 \pm 4.2$ & $8.7 \pm 3.0$ \\
\hline South-East & $13.2 \pm 4.4$ & $18.5 \pm 5.5$ & $9.1 \pm 4.1$ & $9.4 \pm 3.4$ \\
\hline Forest & $13.4 \pm 4.4$ & $17.5 \pm 5.2$ & $9.6 \pm 4.2$ & $7.9 \pm 3.0$ \\
\hline
\end{tabular}

The seasonal course of the air temperatures (Fig. 4a-c) reveals no trend for the daily amplitude and for $\mathrm{T}_{\min }$, but for $\mathrm{T}_{\max }$ an increasing difference between northern and southern sites from spring to autumn. The maximal difference between the clear-cut area and the reference forest site was $4.4^{\circ} \mathrm{C}$ and it was observed at the NE station on sunny day of August 29. Maximal air temperature in the central part of the clear-cut reached $26.0^{\circ} \mathrm{C}$ on this day, and the global radiation was $20.5 \mathrm{MJ} \mathrm{m}^{-2}$ day $^{-1}$.

The values of minimal air temperature (Fig. 4c) were, however, even on clear nights unexpectedly similar at all measuring sites. This could be caused by a horizontal downhill air flow on the clear-cut and into the trunk space of the surrounding spruce forest. The $\mathrm{T}_{\min }$ was at clear-cut sites usually somewhat lower than at the forest site. The SE station tended to show the lowest night temperature, and the greatest difference was observed at the SW station on the clear night of May 20, when minimal air temperature was $2.1^{\circ} \mathrm{C}$ lower than in the forest.

Such differencies may be explained by structure of radiation and energy balances at the clear-cut area and at the reference forest plot. The radiation balance of the clear-cut area (i.e. surfaces of soil and plants) is always positive during the day and negative during night-time. The surface gets more energy than it looses during the day and it looses more energy by long-wave emission than it gains during the night. The surface and the air in $2 \mathrm{~m}$ height at the clear-cut should get warmer during daytime and cooler during night time as compared to the surface (of soil and understorey) and air conditions within the forest, where the radiation balance is much reduced. The daily maximum air and surface temperatures are, therefore, lowest in the forest and highest on the clear-cut while this is reversed for the daily minimum, as our measurement results confirmed (Table 4 and Fig. 4c).

\section{CONCLUSIONS}

The results of the field study in the small clear-cut area in Otterbach showed that the changing sun position during the course of a day and a year resulted in a quite heterogeneous solar irradiance field on the clear cut with higher values at the northern sides differenciated by beech phenology and by the ratio of diffuse sky irradiance to direct solar irradiances.

The soil $(10 \mathrm{~cm}$ depth) temperature is distributed in a similar pattern, which is diverging where it is influenced by dead and active vegetation cover and by soil moisture. The temperature of the $10 \mathrm{~cm}$ soil layer varied most strongly in time and space, because it depends on direct irradiance, on soil heat conductivity and capacity as well as on vegetation cover and its phenology. An increase of up to $4.5^{\circ} \mathrm{C}$ during sunny days certainly influences several ecological processes like for instance the nutrient cycling (e.g. [9, 25, 26]). The spatial range of $2{ }^{\circ} \mathrm{C}$ for the daily maximal soil temperature within our clear-cut of $2-3$ ha fits well into findings of similar measurements in gaps (e.g. [10]), although direct compairisons are difficult because measuring depths as well as sizes of forest openings differed. This spatial heterogenity contributes to a niche differentiation with species tolerating hotter and temporarily drier conditions in the centre and at northern borders of the clear-cut.

Only about half as wide ranged the air temperature on the clear cut area $\left(<1{ }^{\circ} \mathrm{C}\right)$ and between the clear cut and the neighboring spruce stand $\left(<2^{\circ} \mathrm{C}\right)$. This is mainly due to the standard meteorological measuring hight of $2 \mathrm{~m}$ (a.g.l.). For the moving air aggregates the different heat sources at the 


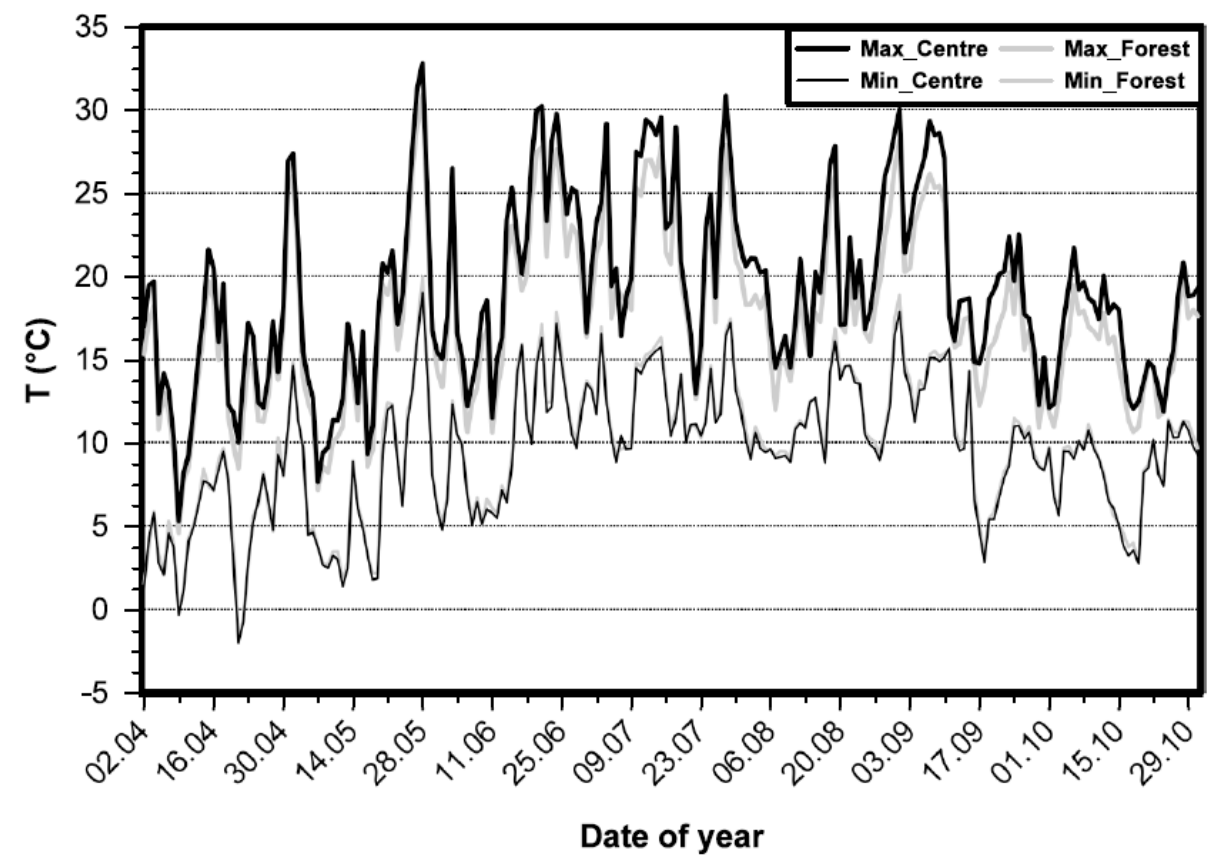

Fig. (4a). Seasonal course of daily maximum and minimum of air temperature $(\mathrm{T})$ measured by stations in the centre of clear-cut area and within the forest for study period from April to October 2005.

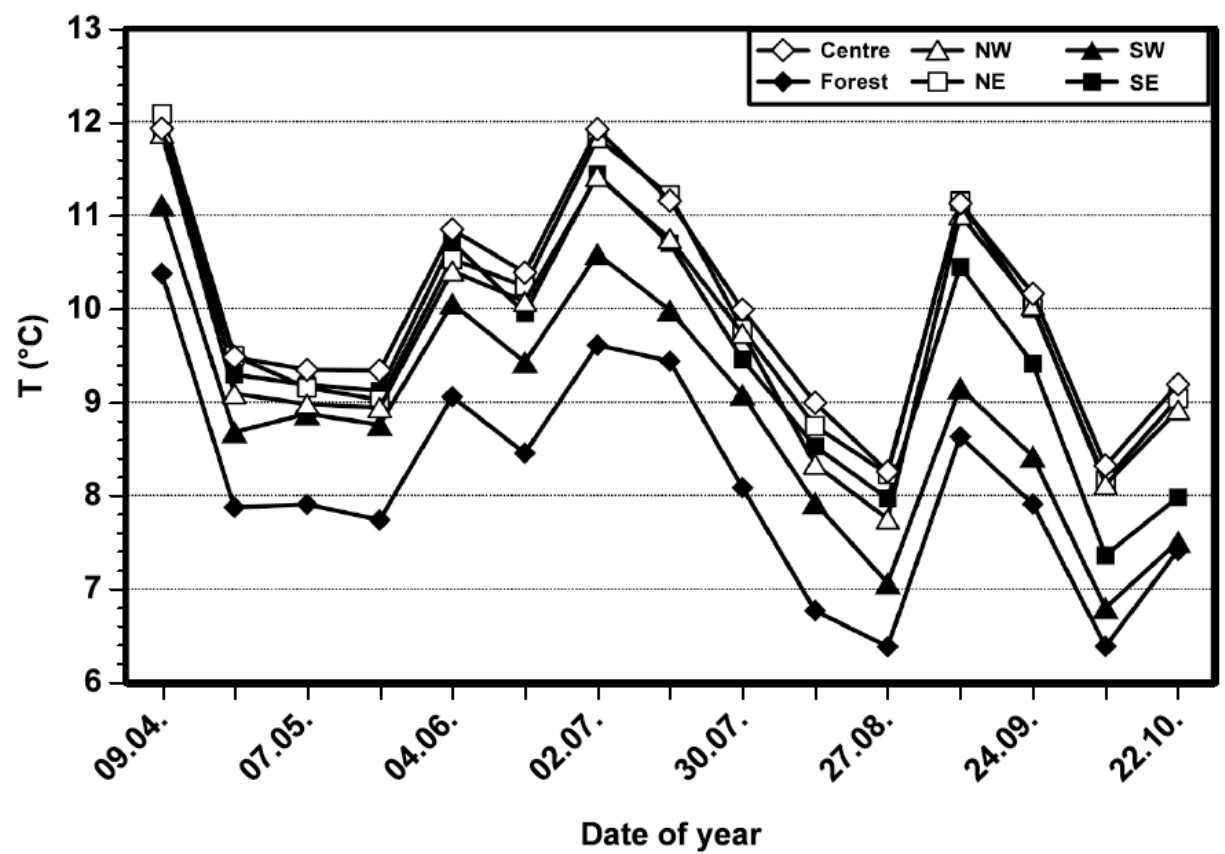

Fig. (4b). Seasonal course of mean daily amplitude (two weeks averaging) of air temperature at five measuring stations on the clear-cut area and at the reference forest plot during the study period from April to October 2005.

ground surface and levels the temperature rapidly by vertical turbulence and horizontal advection. Thus this pattern would have been more heterogeneous at a measuring hight of $20 \mathrm{~cm}$ a.g.1.

For the forest management the main results of this case study may be useful in several ways:

(1) They provide hints for the planning to decrease the risk of sapling mortality and to maximize the success of forest regeneration with this silviculture strategy. If, as in our case, the target is a mixed forest stand of Douglas fir and beech, these two species could be allocated according to radiation and/or soil temperature gradients rather than randomly or regularily on such small clear-cuts.

In the context of an ecosystem management it provides one of most rare examples for measuring the magnitude of environmental spatial gradients, which are relevant for other management objectives, e.g. providing habitat for wildlife species or forest arthropods (see e.g. [27, 28]).

(3) Last but not least such results are accordingly valid in all types of disturbances of compairable size, and 


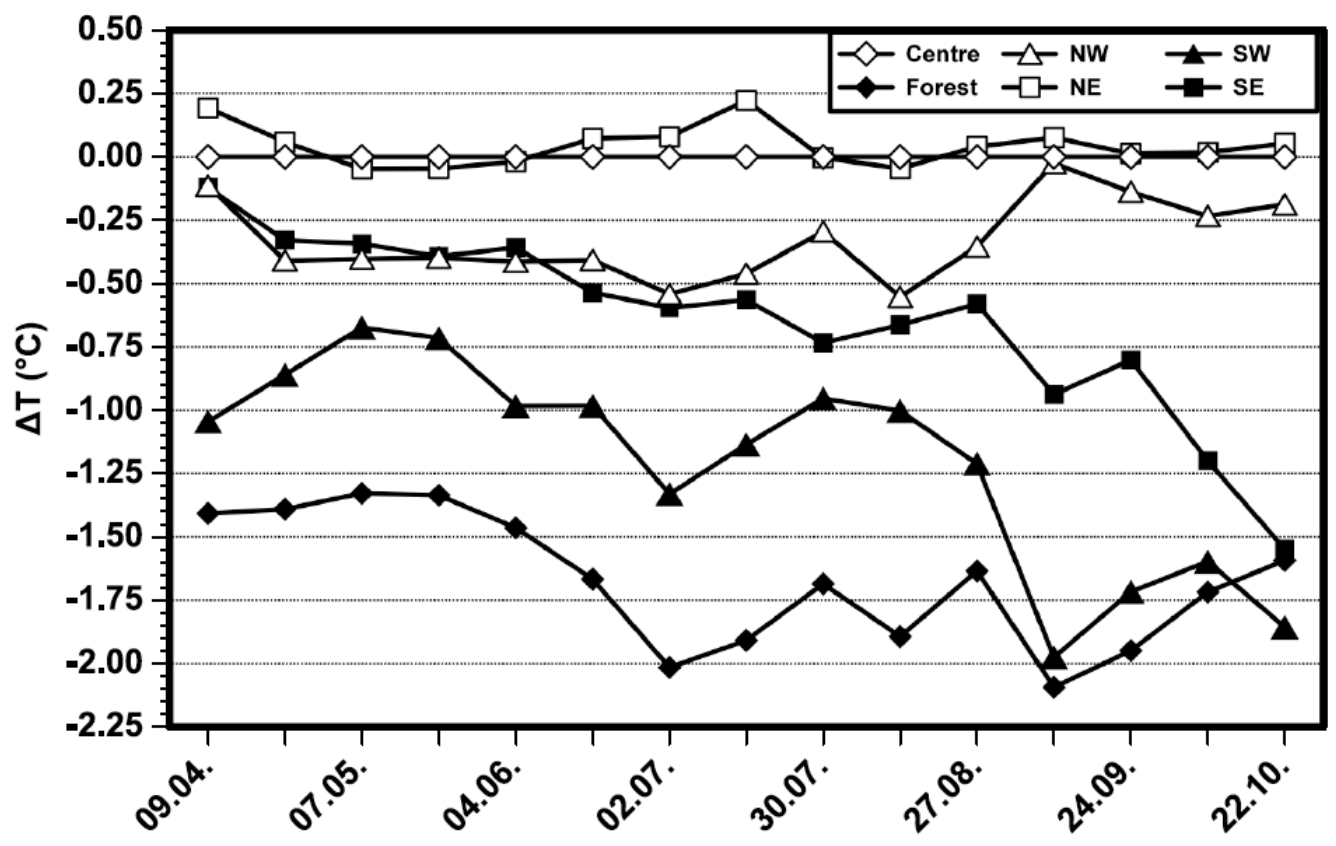

Date of year

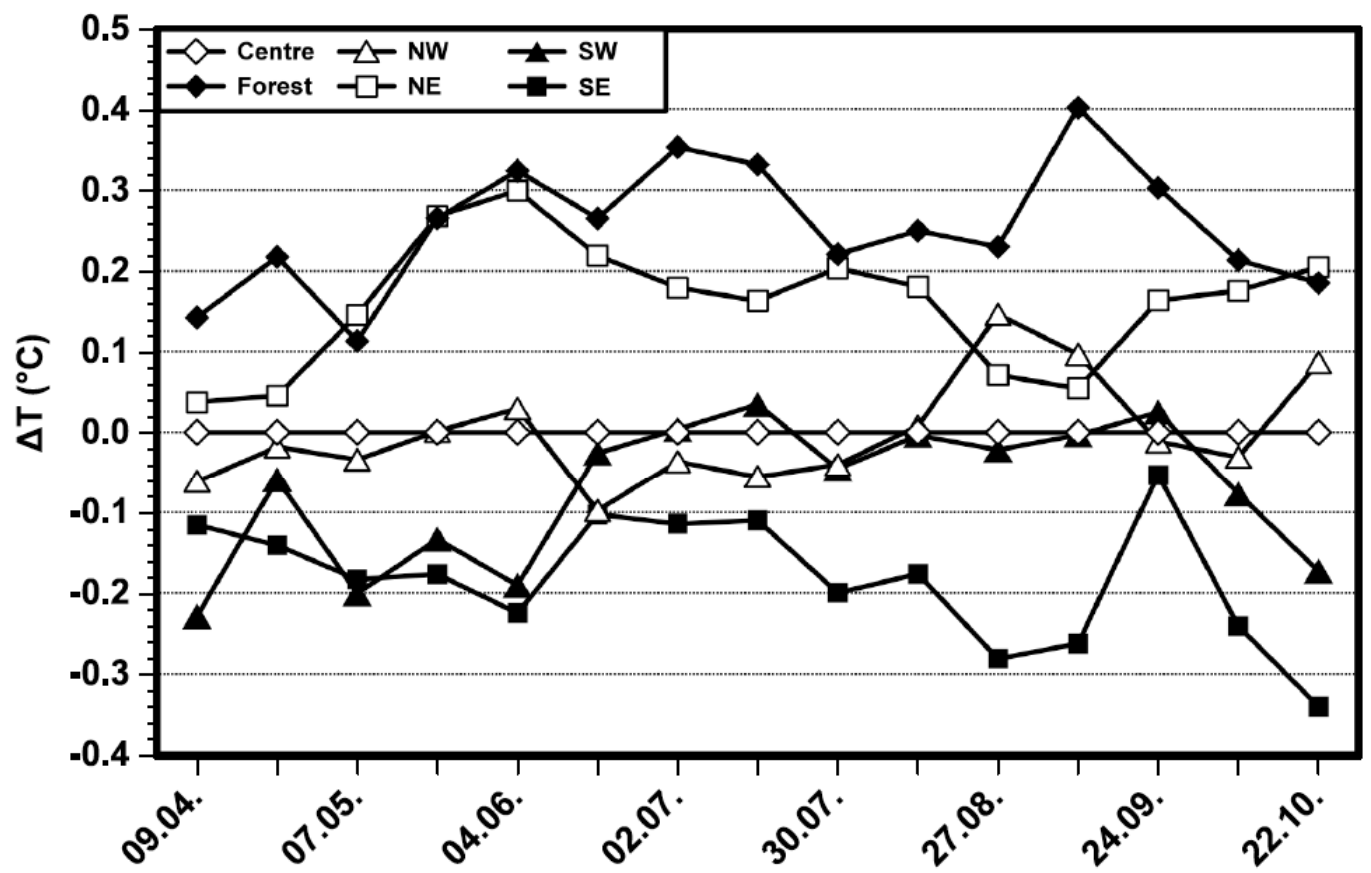

Date of year

Fig. (4c). Seasonal course of mean daily maxima (above) and minima (below) of air temperature at the sites within the clear-cut area and at the reference forest plot during the study period from April to October 2005. Values are plotted as deviations from the respective value at the central station $\Delta \mathrm{T}_{\mathrm{i}}=\mathrm{T}_{\mathrm{i}}-\mathrm{T}_{\text {Centre }}$.

independant of causes like wind throws, forest fires or bark beetle impacts.

\section{ACKNOWLEDGEMENTS}

We thank D. Fellert for the complete installation and his committed maintenance of the microclimate stations, $\mathrm{H}$. Kreilein and $H$. Schäfer for contributing their technical experiences. This study was supported by Deutsche
Forschungsgemeinschaft (German Research Foundation), Grant No. Gr 738/16-2.

\section{REFERENCES}

[1] Spiecker H, Ed. Norway Spruce conversion - options and consequences. Leiden: European Forest Institute 2004.

[2] Röhrig E, Bartsch N, von Lüpke B. Waldbau auf ökologischer Grundlage. $7^{\text {th }}$ ed. Stuttgart: Ulmer 2006. 
[3] Stathers RJ, Black TA, Novak MD. Modelling soil temperature in forest clearcuts using climate station data. Agric For Meteorol 1985; 36: 153-64.

[4] Chen J, Franklin JF, Spies TA. Contrasting microclimates among clearcut, edge, and interior of old-growth Douglas-fir forest. Agric For Meteorol 1993; 63: 219-37.

[5] Potter BE, Ronald M, Teclaw RM, Zasada RM, Teclaw JC. The impact of forest structure on near-ground temperatures during two years of contrasting temperature extremes. Agric For Meteorol 2001; 106(4): 331-6.

[6] Knyazikhin Y, Kranigk J, Miessen G, Panfyorov O, Vygodskaja N, Gravenhorst G. Modelling three-dimensional distribution of photosynthetically active radiation in sloping coniferous stands. Biomass Bioenergy 1996; 11: 189-200.

[7] Mayer H, Holst T, Schindler D. Mikroklima in Buchenbestaenden Teil I: Photosynthetisch aktive Strahlung. Forstwiss Centralbl 2002; 121: 301-21.

[8] Holst Th, Mayer H, Schindler D. Microclimate within beech stands-part II: thermal conditions. Eur J Forest Res 2004; 123: 1328.

[9] Bauhus J, Bartsch R. Mechanisms of carbon and nutrient release and retention in beech forest gaps. II The role of soil microbial biomass. Plant Soil 1995; 168/169: 579-84.

[10] Gray AN, Spies TA, Easter MJ. Microclimatic and soil moisture responses to gap formation in coastal Douglas-fir forests. Can J For Res 2002; 32: 2002.

[11] Ritter E, Dalsgaard L, Einhorn KS. Light, temperature and soil moisture regimes following gap formation in a semi-natural beechdominated forest in Denmark. For Ecol Manage 2005; 206: 15-33.

[12] Carlson DW, Groot A. Microclimate of clear-cut, forest interior, and small openings in trembling aspen forest. Agric For Meteorol 1997; 87: 313-29.

[13] Blennow K. Modelling minimum air temperature in partially and clear felled forests. Agric For Meteorol 1998; 91(3): 223-35.

[14] Geiger R, Aron RH, Todhunter P. The climate near the ground. Wiesbaden: Vieweg 1995.

[15] Venäläinen A, Zeng $\mathrm{H}$, Peltola $\mathrm{H}$, et al. Simulations of the influence of forest management on wind climate on a regional scale. Agric For Meteorol 2004; 123: 149-158.
[16] Sogachev A, Leclerc MY, Karipot A, Zhang G, Vesala T. Effect of clearcuts on footprints and flux measurements above a forest canopy. Agric For Meteorol 2005; 133: 182-96.

[17] Zhang G, Thomas C, Leclerc MY, Karipot A, Gholz HL, Foken T. On the effect of clearcuts on turbulence structure above a forest canopy. Theor Appl Climatol 2007; 88: 133-7.

[18] Wang W, Davis KJ. A numerical study of the influence of a clearcut on eddy-covariance fluxes of $\mathrm{CO}_{2}$ measured above a forest. Agric For Meteorol 2008; 148: 1488-500.

[19] Panferov O, Sogachev A. Influence of gap size on wind damage variables in a forest. Agric For Meteorol 2008; 148: 1869-81.

[20] Kimmins JP. Forest Ecology. $3^{\text {rd }}$ ed. Upper Saddle River, NJ, USA: Prentice Hall 2004.

[21] Schulze ED, Beck E, Müller-Hohenstein K. Pflanzenökologie. Berlin: Spectrum 2002.

[22] SAS Language: Reference Version 9.1.3. Cary, NC, USA: SAS Institute Inc 2004.

[23] Ross J. The radiation regime and architecture of plant stands. The Hague: Junk 1981.

[24] Oliver SA, Oliver HR, Wallace JS, Roberts AM. Soil heat flux and temperature variation with vegetation, soil type and climate. Agric For Meteorol 1987; 39: 257-69.

[25] Brumme R. Mechanisms of carbon and nutrient release and retention in beech forest gaps. III. Environmental regulation of soil respiration and nitrous oxide emissions along a microclimatic gradient. Plant Soil 1995; 168/169: 593-600.

[26] Borken W, Xu YJ, Davidson EA, Beese F. Site and temporal variation of soil respiration in European beech, Norway spruce, and Scots pine forests. Glob Change Biol 2002; 8: 1205-16.

[27] Goßner M, Engel K, Ammer U. Effects of selection felling and gap felling on forest arthropod communities: a case study in a sprucebeech stand of southern Bavaria. Eur J Forest Res 2006; 125: 34560 .

[28] Puettmann KJ, Ammer C. Trends in North American and European regeneration research under the ecosystem management paradigm. Eur J Forest Res 2007; 126: 1-9. 